\title{
Psychometric properties of the Portuguese version of the State-Trait Anxiety Inventory applied to college students: factor analysis and relation to the Beck Depression Inventory
}

\section{Andrade ${ }^{1}$, \\ C. Gorenstein ${ }^{3}$, \\ A.H. Vieira Filho ${ }^{1}$, \\ T.C. Tung ${ }^{2}$ and \\ R. Artes ${ }^{4}$}

\author{
IInstituto de Psiquiatria, Hospital das Clínicas and \\ Departamentos de 2 Psiquiatria, Faculdade de Medicina, \\ ${ }^{3}$ Farmacologia, Instituto de Ciências Biomédicas, and \\ 4Estatística, Instituto de M atemática e Estatística, \\ Universidade de São Paulo, São Paulo, SP, Brasil
}

\section{Correspondence \\ L. Andrade \\ LIM-23, Departamento de Psiquiatria \\ FM, USP \\ Caixa Postal 3671 \\ 01060-970 São Paulo, SP \\ Brasil \\ Fax: + 55-11-3069-6958 \\ E-mail: Ihsgandr@usp.br \\ Research supported by FAPESP (N o. 93/04997-4). C. Gorenstein is supported by CNPq, and T.C. Tung is supported by FAPESP (No. 96/00724-1).}

Received April 10, 2000 Accepted January 29, 2001

\section{Abstract}

The psychometric properties of the Portuguese version of the trait form of the State-Trait Anxiety Inventory (STAI-T) and its relation to the Beck Depression Inventory (BDI) were evaluated in a large Brazilian college student sample containing 845 women and 235 men. STAI-T scores tended to be higher for women, singles, those who work, and subjects under 30 years. Factor analysis of the STAI-T for total sample and by gender yielded two factors: the first representing a mood dimension and the second being related to worrying or cognitive aspects of anxiety. In order to study the relation between anxiety and depression measures, factor analysis of the combination of the 21 BDI items and the 20 STAI-T items was also carried out. The analysis resulted in two factors that were analyzed according to the tripartite model of anxiety and depression. Most of the BDI items (measuring positive affectivity and nonspecific symptoms of depression) were loaded on the first factor and four STAI-T items that measure positive affectivity. The remaining STAI-T items, all of them measuring negative affect, remained in the second factor. Thus, factor 1 represents a depression dimension and factor 2 measures a moodworrying dimension. The findings of this study suggest that, although widely used as an anxiety scale, the STAI-T in fact measures mainly a general negative affect.

\section{Introduction}

The State-Trait Anxiety Inventory (STAI; 1) is probably among the most widely used self-report measures of anxiety in clinical and research settings (2). Spielberger (1) developed the STAI as a self-report scale
Key words

- Strait-Trait Anxiety Inventory

- Factor analysis

- Psychometric properties

- Beck Depression Inventory

- Students measuring two separable components: state anxiety, which refers to a transitory emotional state characterized by subjective feelings of tension that may vary in intensity over time, and trait anxiety, which refers to a relatively stable disposition to respond to stress with anxiety and a tendency to perceive 
a wider range of situations as threatening.

The profiles of the Portuguese versions of the Beck Depression Inventory (BDI) (3) and STAI and the validity of these questionnaires have been recently assessed in different Brazilian patient and college student populations (4-6). The results of these studies supported the construct validity of the Portuguese version of both instruments.

The distinction between state and trait anxiety has been consistently shown in the literature by the factor analysis studies of STAI (e.g., 7-9). However, little attention has been given to the factor structure of each individual state and trait scale.

The objective of the present study was to investigate additional psychometric properties, such as factorial analysis, of the Portuguese version of the trait form of the STAI (STAI-T), considering gender differences, in a larger nonclinical sample. The STAI-T was used because it is a more stable measure than the state form, and unchangeable under different conditions (1). In addition, STAI-T scores were correlated with those of the BDI scale due to the strong relation between measures of depression and anxiety (e.g., 10). Also, a factor analysis was carried out on the combination of the BDI and STAI-T items.

\section{Material and Methods}

\section{Subjects and procedure}

Subjects were 1,080 Brazilian college students (845 women, 235 men; mean age 24.1 years, $\mathrm{SD}=6.4$ year) from the city of São Paulo, the majority attending evening courses. Subjects were asked to voluntarily answer a set of questionnaires in their classrooms at the beginning of their regular classes. We selected academic courses with a predominance of women and oversampled them, since the present study was associated with another one designed to assess physical and psychological symptoms during the last menstrual cycle.

\section{Instruments}

STAI. The Portuguese version of the STAI-T (1) was validated by Biaggio and Natalício (11). Subjects were classified as high and low on trait anxiety, using the group mean $\pm 1 \mathrm{SD}$, respectively.

BDI. The Portuguese version of the 21 items of the revised form of the BDI $(12,13)$ was used. The scale consists of items including symptoms and attitudes with intensities ranging from neutral to a maximum level of severity, ranked from 0 to 3 . We adopted the cut-off scores proposed by Kendall et al. (14) for nonclinical populations, i.e., scores higher than 15 as detecting dysphoria, and scores over 20 as indicative of depression

\section{Statistical analysis}

Comparison by sociodemographic characteristics was performed through $\mathrm{F}$ tests followed by the Tukey $t$-test. The internal consistency for the STAI-T was calculated by Cronbach's alpha coefficient (15). Itemtotal correlations were evaluated in order to identify which items were more associated with the STAI-T total score. Individual item means were compared by the Student $t$-test with Bonferroni adjustments of $\mathrm{P}=0.05$ for the 20 comparisons in order to protect for familywise error rate (individual significant values, $\mathrm{P}<0.003$ ).

Multiple regression analysis was performed to relate STAI-T total score to sex, age and professional activity. STAI-T data were transformed into their fifth roots to minimize the effects of the departure from the assumptions of normality and homoscedasticity of the model's errors.

Spearman correlation coefficients were calculated for the comparison of BDI and STAI-T scores.

Principal component analysis with varimax rotation was performed to assess the factor structure of the STAI-T for the total sample and by gender (16). The same proce- 
dure was applied to the combination of the 41 items of the BDI and STAI-T scales.

\section{Results}

STAI-T scores according to sociodemographic characteristics are given in Table 1. Differences by gender were significant, with women scoring higher than men $(\mathrm{P}<0.01)$. Subjects under 30 years had significantly higher scores than the other age groups $(\mathrm{P}<0.05)$. Singles had higher STAI-T scores than married subjects $(\mathrm{P}<0.05)$. Internal consistency estimated as coefficient alpha was 0.89 for the total sample. Subgroups according to demographic characteristics showed similar coefficients.

Mean STAI-T total scores for subgroups according to the cut-off scores using the group mean \pm 1 SD were: $<33: 28.6 \pm 2.9$ (15.9\%), 33-49: $40.5 \pm 5.4$ (55.3\%), and $>49: 56.7 \pm 6.1(28.8 \%)$.

Multiple regression analysis showed that gender ( 0 if male, 1 if female), work ( 0 if no, 1 if yes) and age were statistically significant $(\mathrm{P}=0.017, \mathrm{P}=0.086$, and $\mathrm{P}<0.001$, respectively) $\left(r^{2}=0.02\right)$. STAI-T scores tended to be higher for women, for those who work and for younger subjects. The final model of multiple regression analysis was: $5 \sqrt{\mathrm{STAI}}=$ $2.162-0.019$ sex +0.013 work -0.002 age .

Table 2 shows STAI-T individual item mean scores and SD and the item-total correlations for total sample and by gender. Women had significantly higher scores than men on items 3, 7, 12 and 20, while men had higher scores than women on item 10, according to Student $t$-test with Bonferroni adjustment. When means according to sex were compared without Bonferroni adjustment women had higher scores than men in nine other items: 2, 6, 9, 11-13, 17-19.

On the basis of factor analysis, the first unrotated factor accounted for $34.2 \%$ of the variance. The second factor accounted for an additional variability of $8.5 \%$. A small contribution to the STAI-T structure was made by each of the remaining factors. Considering loading greater than 0.40 , principal component analysis with varimax rotation suggests that the two STAI-T factors that could be extracted are related to the following items: factor 1 : items 1, 2, 4, 6-8, 10, 13, 15, 16 and 19; factor 2: items 5, 9, 11, 12, 14, 17, 18 and 20.

Cronbach's alpha coefficients for the subscales based on the items related to factors 1 and 2 were 0.84 and 0.81 , respectively. Subscale 1 represents predominantly the mood dimension, while subscale 2 represents the worrying dimension (Table 3 ).

Also two factors were extracted from the factor analysis for the women sub-sample. The first unrotated factor accounted for $33.0 \%$ of the variance and the second factor accounted for an additional variability of 8.5\%. Principal component analysis with varimax rotation suggested that the two STAI$T$ factors that could be extracted were related to the following items: factor 1 : items 1-4, 6$8,10,13,15,16,19$; factor 2 : items $5,8,9$, $11,12,14,17,18,20$.

\begin{tabular}{|c|c|c|c|c|}
\hline \multirow{2}{*}{$\begin{array}{l}\text { Sociodemographic } \\
\text { characteristics }\end{array}$} & \multirow[t]{2}{*}{$\%$} & \multicolumn{3}{|c|}{ STAI-T } \\
\hline & & Mean & SD & $\alpha$ \\
\hline \multicolumn{5}{|l|}{ Age (years) } \\
\hline$<30$ & 87.3 & $43.8^{* *}$ & 10.7 & 0.89 \\
\hline $31-45$ & 11.2 & 40.2 & 11.5 & 0.92 \\
\hline$>45$ & 1.5 & 37.5 & 9.7 & 0.87 \\
\hline \multicolumn{5}{|l|}{ Marital status } \\
\hline $\begin{array}{l}\text { single } \\
\text { married }\end{array}$ & 85.0 & $43.8^{* *}$ & 10.8 & $\begin{array}{l}0.89 \\
0.89\end{array}$ \\
\hline $\begin{array}{l}\text { married } \\
\text { other }\end{array}$ & $\begin{array}{r}13.2 \\
1.8\end{array}$ & $\begin{array}{l}40.1 \\
39.4\end{array}$ & $\begin{array}{l}10.7 \\
11.7\end{array}$ & $\begin{array}{l}0.09 \\
0.94\end{array}$ \\
\hline \multicolumn{5}{|l|}{ Gender } \\
\hline male & 22.1 & 41.6 & 11.5 & 0.91 \\
\hline female & 77.9 & $43.7^{*}$ & 10.7 & 0.89 \\
\hline \multicolumn{5}{|c|}{ Professional occupation } \\
\hline yes & 74.2 & 43.3 & 11.0 & 0.89 \\
\hline no & 25.8 & 42.9 & 10.7 & 0.89 \\
\hline Total & & 43.4 & 10.8 & 0.89 \\
\hline
\end{tabular}


Table 2 - State-Trait Anxiety Inventory (trait form) mean scores and standard deviations (SD) for individual items and item-total correlations for total sample and by gender.

Means and SD were calculated considering only inventories without missing values. $* \mathrm{P}<0.05$ significantly different from men's mean (Student t-test considering Bonferroni adjustment).

\begin{tabular}{|c|c|c|c|c|c|c|c|c|c|}
\hline \multirow[t]{2}{*}{ Item } & \multicolumn{2}{|c|}{ Males } & \multicolumn{2}{|c|}{ Females } & \multicolumn{2}{|c|}{ Total } & \multicolumn{3}{|c|}{ Item-total correlation } \\
\hline & Mean & SD & Mean & SD & Mean & SD & Male & Female & Total \\
\hline 1 & 1.90 & 0.87 & 1.81 & 0.81 & 1.84 & 0.82 & 0.64 & 0.49 & 0.52 \\
\hline 2 & 2.06 & 0.89 & 2.22 & 0.86 & 2.19 & 0.87 & 0.45 & 0.38 & 0.40 \\
\hline 3 & 1.53 & 0.67 & $1.97 *$ & 0.78 & 1.87 & 0.77 & 0.40 & 0.49 & 0.47 \\
\hline 4 & 1.98 & 1.04 & 1.93 & 1.03 & 1.94 & 1.04 & 0.50 & 0.51 & 0.50 \\
\hline 5 & 1.95 & 0.98 & 1.88 & 0.96 & 1.91 & 0.96 & 0.52 & 0.45 & 0.46 \\
\hline 6 & 2.60 & 0.99 & 2.76 & 0.97 & 2.74 & 0.98 & 0.52 & 0.34 & 0.39 \\
\hline 7 & 2.26 & 1.00 & $2.48^{*}$ & 0.94 & 2.44 & 0.95 & 0.66 & 0.55 & 0.58 \\
\hline 8 & 1.89 & 0.91 & 1.93 & 0.90 & 1.93 & 0.90 & 0.46 & 0.55 & 0.52 \\
\hline 9 & 2.00 & 0.99 & 2.19 & 1.04 & 2.15 & 1.04 & 0.40 & 0.49 & 0.47 \\
\hline 10 & 2.18 & 1.00 & $1.91 *$ & 0.91 & 1.97 & 0.93 & 0.69 & 0.56 & 0.57 \\
\hline 11 & 2.44 & 0.98 & 2.63 & 1.00 & 2.60 & 0.99 & 0.57 & 0.54 & 0.55 \\
\hline 12 & 1.83 & 0.90 & $2.05^{*}$ & 0.95 & 2.00 & 0.94 & 0.57 & 0.51 & 0.53 \\
\hline 13 & 2.23 & 0.93 & 2.40 & 0.96 & 2.37 & 0.95 & 0.73 & 0.59 & 0.62 \\
\hline 14 & 2.26 & 1.07 & 2.29 & 1.04 & 2.29 & 1.05 & 0.28 & 0.20 & 0.22 \\
\hline 15 & 1.84 & 0.86 & 1.96 & 0.84 & 1.94 & 0.84 & 0.67 & 0.63 & 0.64 \\
\hline 16 & 2.36 & 1.02 & 2.23 & 0.94 & 2.27 & 0.95 & 0.73 & 0.62 & 0.64 \\
\hline 17 & 2.00 & 0.91 & 2.18 & 0.94 & 2.15 & 0.94 & 0.43 & 0.52 & 0.50 \\
\hline 18 & 1.89 & 0.93 & 2.10 & 1.00 & 2.06 & 0.99 & 0.63 & 0.60 & 0.61 \\
\hline 19 & 2.15 & 1.00 & 2.31 & 0.95 & 2.28 & 0.97 & 0.64 & 0.53 & 0.56 \\
\hline 20 & 2.26 & 0.98 & 2.49* & 0.95 & 2.46 & 0.96 & 0.61 & 0.50 & 0.53 \\
\hline Total & 41.86 & 11.59 & 43.84 & 10.57 & 43.39 & 10.83 & & & \\
\hline
\end{tabular}

Table 3 - State-Trait Anxiety Inventory (trait form) item factor loadings after varimax rotation for the total sample and according to sex.

Only loadings above 0.40 (bold) were considered to significantly contribute to a factor.

\begin{tabular}{|c|c|c|c|c|c|c|}
\hline \multirow[t]{2}{*}{ Item } & \multicolumn{2}{|c|}{ Total sample } & \multicolumn{2}{|c|}{ Women } & \multicolumn{2}{|c|}{ Men } \\
\hline & Factor 1 & Factor 2 & Factor 1 & Factor 2 & Factor 1 & Factor 2 \\
\hline 1. Feel pleasant & 0.76 & 0.01 & 0.72 & 0.03 & 0.84 & -0.05 \\
\hline 2. Tire quickly & 0.40 & 0.23 & 0.40 & 0.20 & 0.45 & 0.22 \\
\hline 3. Crying & 0.38 & 0.38 & 0.42 & 0.38 & 0.42 & 0.17 \\
\hline 4. Happy as others & 0.48 & 0.31 & 0.48 & 0.33 & 0.50 & 0.24 \\
\hline 5. Can't make up mind & 0.30 & 0.44 & 0.23 & 0.50 & 0.47 & 0.33 \\
\hline 6. Feel rested & 0.47 & 0.13 & 0.46 & 0.09 & 0.58 & 0.16 \\
\hline 7. Calm, cool, and collected & 0.63 & 0.24 & 0.64 & 0.20 & 0.68 & 0.26 \\
\hline 8. Difficulties piling up & 0.42 & 0.40 & 0.42 & 0.44 & 0.43 & 0.28 \\
\hline 9. Worry too much & 0.10 & 0.71 & 0.12 & 0.70 & 0.10 & 0.72 \\
\hline 10. Happy & 0.80 & 0.04 & 0.79 & 0.05 & 0.81 & 0.11 \\
\hline 11. Take things hard & 0.22 & 0.69 & 0.21 & 0.68 & 0.32 & 0.66 \\
\hline 12. Lack self-confidence & 0.35 & 0.49 & 0.33 & 0.49 & 0.48 & 0.41 \\
\hline 13. Feel secure & 0.60 & 0.34 & 0.57 & 0.33 & 0.73 & 0.31 \\
\hline 14. Avoid crises or difficulty & -0.01 & 0.42 & -0.05 & 0.42 & 0.06 & 0.52 \\
\hline 15. Feel blue & 0.66 & 0.31 & 0.63 & 0.33 & 0.75 & 0.16 \\
\hline 16. Content & 0.78 & 0.16 & 0.78 & 0.16 & 0.79 & 0.21 \\
\hline 17. Unimportant thoughts bother & 0.13 & 0.71 & 0.16 & 0.70 & 0.11 & 0.75 \\
\hline 18. Take disappointments keenly & 0.35 & 0.62 & 0.31 & 0.65 & 0.55 & 0.42 \\
\hline 19. Steady person & 0.63 & 0.23 & 0.60 & 0.23 & 0.74 & 0.14 \\
\hline 20. Tension or turmoil & 0.27 & 0.59 & 0.24 & 0.58 & 0.44 & 0.55 \\
\hline
\end{tabular}


Cronbach's alpha coefficients for the subscales based on the items related to factors 1 and 2 were 0.86 and 0.80 , respectively. Factor 1 represents predominantly the mood dimension and factor 2 represents the worrying dimension (Table 3 ).

According to the factor analysis for the men's sub-sample, the first unrotated factor accounted for $38.6 \%$ of the variance and the second factor accounted for an additional variability of $8.2 \%$. Principal component analysis with varimax rotation suggested that the two STAI-T factors that could be extracted were related to the following items: factor 1: items 1-8, 10, 12, 13, 15, 16, 18-20; factor 2: items 9, 11, 12, 14, 17, 18, 20.

Cronbach's alpha coefficients for the subscales based on the items related to factors 1 and 2 were 0.91 and 0.78 , respectively. Factor 1 represents the mood-insecurity dimension, while factor 2 represents the worrying dimension (Table 3 ).

Scores on the BDI and STAI-T were significantly correlated $(\mathrm{r}=0.66, \mathrm{P}<0.001)$. Correlation between subgroup scores on each test reached significance between low BDI scores (0-15) and low scores on the STAI-T $(20-33)(\mathrm{r}=0.23 ; \mathrm{P}=0.002)$, low BDI scores and medium scores on the STAI-T (34-49) ( $\mathrm{r}$ $=0.23 ; \mathrm{P}<0.001)$, medium BDI scores (1620 ) with high scores on the STAI-T $(>49)$ ( $\mathrm{r}$ $=0.17 ; \mathrm{P}=0.01)$, high scores on the BDI $(\geq 21)$ and high scores on the STAI-T $(r=$ $0.35 ; \mathrm{P}<0.001$ ).

Table 4 shows the factor analysis for the combination of the 41 items of the BDI and STAI-T scales. Two factors were extracted from this factor analysis. The first unrotated factor accounted for $26.0 \%$ of the variance and the second accounted for an additional variability of $5.5 \%$. A small contribution to the STAI-T structure was made by each of the remaining factors. Principal component analysis with varimax rotation suggested that the two factors that could be extracted were related to the following items: factor 1: BDI items, 1-10, 12, 13, 15-18 and 20; STAI-T items, 1, 10, 15 and 16; factor 2: BDI items, none; STAI-T items, 1, 3-5, 7-13, 15-20.

Cronbach's alpha coefficients for the subscales based on the items related to factors 1 and 2 were 0.89 in both cases. Factor 1 represents the depression dimension and factor 2 represents the mood-worrying dimension (Table 4).

Table 4 - Factor analysis for the combination of the 41 items of the Beck Depression Inventory and State-Trait Anxiety Inventory (trait form) scales.

Only loadings above 0.40 (bold) were considered to significantly contribute to a factor.

\begin{tabular}{lcc}
\hline & Factor 1 & Factor 2 \\
\hline 1. Sadness & 0.60 & 0.19 \\
2. Pessimism & 0.61 & 0.16 \\
3. Sense of failure & 0.57 & 0.31 \\
4. Lack of satisfaction & 0.60 & 0.25 \\
5. Guilty feelings & 0.52 & 0.21 \\
6. Sense of punishment & 0.49 & 0.12 \\
7. Self-dislike & 0.55 & 0.28 \\
8. Self-accusations & 0.44 & 0.28 \\
9. Suicidal wishes & 0.56 & 0.15 \\
10. Crying spells & 0.45 & 0.19 \\
11. Irritability & 0.36 & 0.14 \\
12. Social withdrawal & 0.54 & 0.18 \\
13. Indecisiveness & 0.56 & 0.19 \\
14. Distortion of body image & 0.34 & 0.20 \\
15. Work inhibition & 0.59 & 0.22 \\
16. Sleep disturbance & 0.44 & 0.01 \\
17. Fatigability & 0.53 & 0.13 \\
18. Loss of appetite & 0.44 & 0.07 \\
19. Weight loss & 0.19 & 0.03 \\
20. Somatic preoccupation & 0.40 & 0.06 \\
21. Loss of libido & 0.32 & 0.05 \\
1. Feel pleasant & 0.41 & 0.42 \\
2. Tire quickly & 0.30 & 0.31 \\
3. Crying & 0.27 & 0.46 \\
4. Happy as others & 0.29 & 0.47 \\
5. Can't make up mind & 0.18 & 0.49 \\
6. Feel rested & 0.31 & 0.30 \\
7. Calm, cool, and collected & 0.38 & 0.49 \\
8. Difficulties piling up & 0.29 & 0.49 \\
9. Worry too much & 0.01 & 0.62 \\
10. Happy & 0.42 & 0.47 \\
11. Take things hard & 0.10 & 0.65 \\
12. Lack self-confidence & 0.14 & 0.59 \\
13. Feel secure & 0.25 & 0.65 \\
14. Avoid crises or difficulty & -0.04 & 0.33 \\
15. Feel blue & 0.43 & 0.57 \\
16. Content & 0.40 & 0.55 \\
17. Unimportant thoughts bother & 0.01 & 0.64 \\
18. Take disappointments keenly & 0.21 & 0.65 \\
19. Steady person & 0.30 & 0.53 \\
20. Tension or turmoil & 0.21 & 0.56 \\
& &
\end{tabular}




\section{Discussion}

The highest anxiety scores were found among women, singles, those who work, and subjects under 30 years. This is in agreement with other STAI reports (e.g., 17,18). Also, epidemiological studies have shown higher anxiety complaints in younger samples compared to older ones $(19,20)$.

Differences by gender, consisting of higher scores for women than men, are also in agreement with other studies (e.g., 1,10, 17,21-23). Individual item scores showed a trend towards higher scores for women in the majority of individual items, some of them reaching statistical significance. Itemtotal correlations were in the range of 0.40 and 0.60 for most items, with no consistent difference between men and women.

The reliability of the questionnaire, assessed by Cronbach's alpha coefficient and item-total correlation was high, indicating that the items of the Portuguese version of the STAI-T are highly homogenous.

In contrast to findings of gender differences in the expression of depressive symptoms in the factor analysis of BDI done on this sample (6), we found a closely similar pattern in the distribution of items in the STAI-T factor analysis for both men and women. However, in the first factor, men seemed to combine more items indicative of insecurity besides mood-related items, than women.

Our factor analysis of the STAI-T for total sample and by gender yielded two factors. The first represented mainly a mood dimension and the second was closely related to worrying or cognitive aspects of anxiety. The finding that most of the variance of the scale is explained by a factor that measures a depression dimension was also reported by Bieling et al. (24). These investigators found a two-factor solution: 10 out of their 13 items loading in the first factor (depression content) and 6 out of their 7 items loading in factor two (anxiety content) agree with our results. In contrast, different results were reported by Pasquali et al. (25) for another Brazilian sample of 3449 individuals (2266 men). According to a principal component analysis, they found two components, called stress (13 items) and emotional stability (7 items). Their STAI-T first component was composed of items related to indecision and worrying, whereas second component items were related to well-being. The items associated with these components were not similar to those obtained in the present sample. The higher prevalence of men in Pasquali's sample (65.7\%) and the stressful situation of data collection (individuals answered the questionnaire while participating in a job selection procedure) might explain the lack of concordance between the two studies.

The significant correlation between BDI and STAI-T total scores was expected (e.g., 10,26-32). This may be due to the psychometric weakness of the scales used rather than to a real comorbidity or weakness of the anxiety or depression constructs (33).

In order to clarify whether this correlation is due to a low STAI-T discriminant validity or to a nonspecific distress factor shared by both anxiety and depression (34), we conducted a factor analysis pooling together the $21 \mathrm{BDI}$ items and the 20 STAI-T items. This factor analysis resulted in two factors. The first included most of the BDI items (except for irritability, distortion of body image, weight loss, and loss of libido) and four STAI-T items (feel pleasant, happy, feel blue, and content). The second included 17 of the 20 STAI-T items, and no BDI item. The BDI items excluded from the first factor are those more related to physical symptoms of depression, whereas the STAI-T items included in this factor are clearly related to positive affectivity.

To better understand the meaning of these two factors we analyzed them according to the tripartite model (35), where anxiety and depression are considered to have an over- 
lapping component, called negative affect, represented by nonspecific symptoms, such as irritability and tension; and specific features of each construct - low levels of positive affect for depression (symptoms such as anhedonia), and physiological hyperarousal for anxiety (e.g., sweating, tachycardia).

According to this approach, most BDI items loading in factor 1 are depression specific (3 items) and nonspecific (8 items) and the four STAI-T items are related to positive affect, indicating that factor 1 is associated with depression.

On the other hand, factor 2 (mood-worrying dimension) measures the nonspecific component of anxiety and depression. In fact, none of the 20 STAI-T items measures specific features of anxiety: 15 items correspond to the measure of general negative affect, and 5 measure positive affectivity.
These results apply to these Brazilian college students and cannot be generalized to patient populations.

An important finding of the present study is that the STAI-T, which is widely used as an anxiety scale, in fact measures primarily a general negative affect. Although this can be viewed as a drawback when considering the anxiety specific construct, the STAI-T proved to be a good measure of general psychopathology. The importance of this construct has been consistently appearing in recent studies in the community as a marker that predicts high impairment and comorbidity in anxiety and depressive disorders (36,37). Whether the presence of general negative affectivity construct measured by the STAI$\mathrm{T}$ could predict severity remains to be further investigated in clinical samples.

\section{References}

1. Spielberger $C D$, Gorsuch RL \& Lushene RE (1970). Manual for the State-Trait Anxiety Inventory. Consulting Psychologists Press, Palo Alto, CA.

2. Keedwell P \& Snaith RP (1996). What do anxiety scales measure? Acta Psychiatrica Scandinavica, 93: 177-180.

3. Beck AT, Ward CH, Mendelson M, Mock J \& Erbaugh G (1961). An inventory for measuring depression. Archives of General Psychiatry, 4: 53-63.

4. Gorenstein C, Pompéia $S \&$ Andrade L (1995). Scores of Brazilian university students on the Beck Depression Inventory and the State-Trait Anxiety Inventory. Psychological Reports, 77: 635-641.

5. Gorenstein C \& Andrade L (1996). Validation of a Portuguese version of the Beck Depression Inventory and the State-Trait Anxiety Inventory in Brazilian subjects. Brazilian J ournal of Medical and Biological Research, 29: 453-457.

6. Gorenstein C, Andrade L, Vieira Filho AHG, Tung TC \& Artes R (1999). Psychometric properties of the Portuguese version of the Beck Depression Inventory on Brazilian college students. J ournal of Clinical Psychology, 55: 553-562.

7. Barker BM, Barker HR \& Wadsworth AP (1977). Factor analysis of the items of the state-trait anxiety inventory. J ournal of Clinical Psychology, 33: 450-455.

8. Spielberger $C D$, Vagg $P R$, Barker $L R$, Donham GW \& Westberry LG (1980). Factor structure of the State-Trait Anxiety Inventory. In: Sarason IG \& Spielberger CD (Editors), Stress and Anxiety. Vol. 7. Hemisphere, Washington, DC, 95-109.

9. Iwata N, Mishima N, Shimizu T, Mizoue T, Fukuhara M, Hidano T \& Spielberger CD (1998). Positive and negative affect in the factor structure of the State-Trait Anxiety Inventory for J apanese workers. Psychological Reports, 82: 651-656.

10. Tanaka-Matsumi J \& Kameoka VA (1986). Reliabilities and concurrent validities of popular self-report measures of depression, anxiety, and social desirability. J ournal of Consulting and Clinical Psychology, 54: 328-333.

11. Biaggio AMB \& Natalício L (1979). Manual para o Inventário de Ansiedade TraçoEstado (IDATE). Centro Editor de Psicologia Aplicada-CEPA, Rio de J aneiro, RJ , Brazil.

12. Beck AT, Rush AJ, Shaw BF \& Emery G (1979). Cognitive Therapy of Depression. Guilford, New York.

13. Beck AT, Rush AJ, Shaw BF \& Emery G (1982). Terapia Cognitiva da Depressão.
Zahar, Rio de J aneiro, RJ , Brazil.

14. Kendall PC, Hollon SD, Beck AT, Hammen CL \& Ingram RE (1987). Issues and recommendations regarding use of the Beck Depression Inventory. Cognitive Therapy and Research, 11: 289-299.

15. Cronbach LJ (1951). Coefficient alpha and the internal structure of tests. Psychometrika, 16: 297-335.

16. J ohnson RA \& Wichern DW (1992). Applied Multivariate Statistical Analysis. 3rd edn. Prentice Hall, New York.

17. Nakazato K \& Shimonaka Y (1989). The J apanese State-Trait Anxiety Inventory: age and sex differences. Perceptual and Motor Skills, 69: 611-617.

18. Stanley MA, Beck J G \& Zebb BJ (1996). Psychometric properties of four anxiety measures in older adults. Behaviour Research and Therapy, 34: 827-838.

19. Regier DA, Boyd J H, Burke J rJ D, Rae DS, Myers J K, Kramer M, Robins LN, George LK, Karno M \& Locke BZ (1988). Onemonth prevalence of mental disorders in the United States. Based on five Epidemiologic Catchment Area sites. Archives of General Psychiatry, 45: 977-986.

20. Andrade L, Lolio C, Gentil V \& Laurenti R (1999). Epidemiologia dos transtornos mentais em uma área de captação da 
cidade de São Paulo. Revista de Psiquiatria Clínica, 26: 257-261.

21. Rodrigo G \& Lusiardo M (1988). Note on the reliability and concurrent validity of the Spanish version of the State-Trait Anxiety Inventory. Perceptual and Motor Skills, 67: 926.

22. Oei TP, Evans L \& Crook GM (1990). Utility and validity of the STAI with anxiety disorder patients. British J ournal of Clinical Psychology, 29: 429-432.

23. McCleary R \& Zucker EL (1991). Higher trait and state-anxiety in female law students than in male law students. Psychological Reports, 68: 1075-1078.

24. Bieling PJ, Antony MM \& Swinson RP (1998). The State-Trait Anxiety Inventory, Trait version: structure and content reexamined. Behaviour Research and Therapy, 36: 777-788.

25. Pasquali L, Pinelli J unior B \& Solha AC (1994). Contribuição à validade e normatização da escala de ansiedade traço-estado do IDATE. Psicologia: Teoria e Pesquisa, 10: 411-420.

26. Mendels J, Weinstein $\mathrm{N} \&$ Cochrane $\mathrm{C}$ (1972). The relationship between depression and anxiety. Archives of General Psy- chiatry, 27: 649-653.

27. Mathew RJ , Swihart AA \& Weinman ML (1982). Vegetative symptoms in anxiety and depression. British J ournal of Psychiatry, 141: 162-165.

28. Gotlib IH (1984). Depression and general psychopathology in university students. J ournal of Abnormal Psychology, 93: 1930.

29. Barlow DH, DiNardo PA, Vermilyea BB, Vermilyea J \& Blanchard EB (1986). Comorbidity and depression among the anxiety disorders: issues in diagnosis and classification. J ournal of Nervous and Mental Disease, 174: 63-72.

30. Riskind J H, Beck AT, Brown G \& Steer RA (1987). Taking the measure of anxiety and depression. Validity of the reconstructed Hamilton Scales. J ournal of Nervous and Mental Disease, 175: 474-479.

31. Beck AT, Steer RA \& Garbin MG (1988). Psychometric properties of the Beck Depression Inventory: twenty-five years of evaluation. Clinical Psychology Review, 8: 77-100.

32. Beck AT, Epstein N, Brown $G \&$ Steer RA (1988). An inventory for measuring clinical anxiety: psychometric properties. J our- nal of Consulting and Clinical Psychology, 56: 893-897.

33. Endler NS, Cox BJ , Parker J DA \& Bagby RM (1992). Self-reports of depression and state-trait anxiety; evidence for differential assessment. J ournal of Personality and Social Psychology, 63: 832-838.

34. Clark LA \& Watson D (1991). Tripartite model of anxiety and depression: Psychometric evidence and taxonomic implications. J ournal of Abnormal Psychology, 3: 316-336.

35. Watson D \& Clark LA (1984). Negative affectivity: the disposition to experience aversive emotional states. Psychology Bulletin, 96: 465-490.

36. Curtis GC, Magee WJ, Eaton WW, Wittchen HU \& Kessler RC (1998). Specific fears and phobias. Epidemiology and classification. British J ournal of Psychiatry, 173: 212-217.

37. Nestadt G, Bienvenu OJ , Cai G, Samuels J \& Eaton WW (1998). Incidence of obsessive-compulsive disorder in adults. J ournal of Nervous and Mental Disease, 186: $401-406$ 